Check for updates

Cite this: RSC Adv., 2017, 7, 51858

Received 3rd October 2017

Accepted 2nd November 2017

DOI: 10.1039/c7ra10921k

rsc.li/rsc-advances

\section{A highly active and thermally stable 6,13-dihydro- 6,13-ethanopentacene-15,16-diimine nickel(II) complex as catalyst for norbornene polymerization}

\author{
Ping Huo, ${ }^{* a}$ Jingbo Li, ${ }^{a}$ Wanyun Liu, (D) *a Guangquan Mei ${ }^{a}$ and Xiaohui He (D) ${ }^{b}$
}

The 6,13-dihydro-6,13-ethanopentacene-15,16-diimine nickel(॥) complex was synthesized and characterized. The nickel complex exhibited high activity toward the homopolymerization of norbornene and copolymerization of norbornene with 5-norbornene-2-carboxylic acid methyl ester in the presence of $\mathrm{B}\left(\mathrm{C}_{6} \mathrm{~F}_{5}\right)_{3}$. It was observed that the nickel catalyst with large steric hindrance from polycyclic aromatic systems on the backbone was found to exhibit good thermal stability and afford high incorporation of polar monomers in norbornene copolymerization.

\section{Introduction}

The norbornene (NB) (bicyclo[2.2.1]hept-2-ene) addition polymer exhibits excellent dielectric properties, optical transparency and rather high thermal stability, which has been of great interest over the past decade. ${ }^{1-3}$ It is well-known that the NB polymerization reaction can be efficiently carried out using conventional Ziegler-Natta catalysts, ${ }^{4,5}$ metallocene catalysts ${ }^{6,7}$ and late-transition metal catalysts. ${ }^{8-14}$ Recently, the latetransition metal catalysts have shown lower oxophilicity and resistance toward polar functionalities, which resulted in renewed interest. The common late transition metal catalysts are nickel(II) and palladium(II) complexes. Since $\boldsymbol{\alpha}$-diimine nickel, palladium complexes have been successfully developed by Brookhart and his collaborators and show high catalytic activity for $\alpha$-olefin polymerization. ${ }^{15-17} \mathrm{~A}$ series of breakthroughs have been made in this field, mainly involving other late transition metal $\alpha$-diimine catalysts. ${ }^{18-21}$

A key insight from these early studies is that the incorporation of bulky axial substituents in the $\alpha$-diimine ligand is crucial in the enhancement of thermally stable of catalysts, because the bulky substituents can hinder the rotation of aniline moieties and protect the metal center effectively. In addition, these catalysts can produce polyolefins with high molecular weight and have good tolerance toward polar groups. Since its discovery, this class of bulky catalysts has attracted a tremendous amount of interest. Much of the work is focused on changing the $\mathrm{N}$-bound aryl group ${ }^{22-25}$ or modifying the backbone, ${ }^{26-28}$ including the use of axial donating diimine ligands. A

${ }^{a}$ Key Laboratory of Jiangxi University for Applied Chemistry and Chemical Biology, Yichun University, Yichun 336000, China. E-mail: ycxyhuoping@163.com; liuwanyun2006@163.com

${ }^{b}$ Department of Chemistry/Institute of Polymers, Nanchang University, 999 Xuefu Avenue, Nanchang 330031, China macro cyclic ligand by connecting the aryl substituents of 2,6diarylphenylimino moieties using ethylene tether was synthesized by Guan and co-workers. ${ }^{29}$ Both the cyclophane-based $\mathrm{Ni}(\mathrm{II})$ and $\mathrm{Pd}(\mathrm{II})$ catalysts showed significantly higher thermal stability than the acyclic analogs. Wu have synthesized $\alpha$-diimine nickel catalyst with a bulky camphyl backbone, which show good thermal stability toward olefin polymerizations and obtain special branched polyolefin. ${ }^{30,31} \mathrm{~A}$ series of $\mathrm{Ni}(\mathrm{II})$ dihalide complexes bearing unsymmetrical $\alpha$-diimine ligands were synthesized and exhibited high activity and thermal stability in olefin polymerization. ${ }^{32,33}$ Recently, we have successfully explored a type of thermostable and high activity threedimensional geometry 9,10-dihydro-9,10-ethanoanthracene11,12-diimine $\mathrm{Ni}(\mathrm{II})$ and $\mathrm{Pd}(\mathrm{II})$ catalysts toward norbornene polymerization. ${ }^{34,35}$ The three-dimensional geometry $\alpha$-diimine metal catalysts with big steric hindrance on the backbone were capable of norbornene polymerization at $120{ }^{\circ} \mathrm{C}$ only in the presence of $\mathrm{B}\left(\mathrm{C}_{6} \mathrm{~F}_{5}\right)_{3}$ and afford high incorporation of polar monomer.

Based on the above results, we herein continue to increase the hindrance on the backbone of $\alpha$-diimine late transition metal catalyst and synthesized the 6,13-dihydro-6,13ethanopentacene-15,16-diimine nickel(II) complex with large steric hindrance of polycyclic aromatic systems. The catalytic activity of complex with only $\mathrm{B}\left(\mathrm{C}_{6} \mathrm{~F}_{5}\right)_{3}$ as cocatalyst in NB polymerization were also investigated. The nickel(II) complex appeared to be thermostable and highly active catalyst on the NB homopolymerization and copolymerization of NB and 5norbornene-2-carboxylic acid methyl ester $\left(\mathrm{NB}-\mathrm{COOCH}_{3}\right)$.

\section{Results and discussion}

Synthesis of complexes $\mathrm{NiLBr}_{2}$

The stoichiometric condensation reaction of 6,13-dihydro-6,13ethanopentacene-15,16-dione and 2,6-dimethyl aniline 


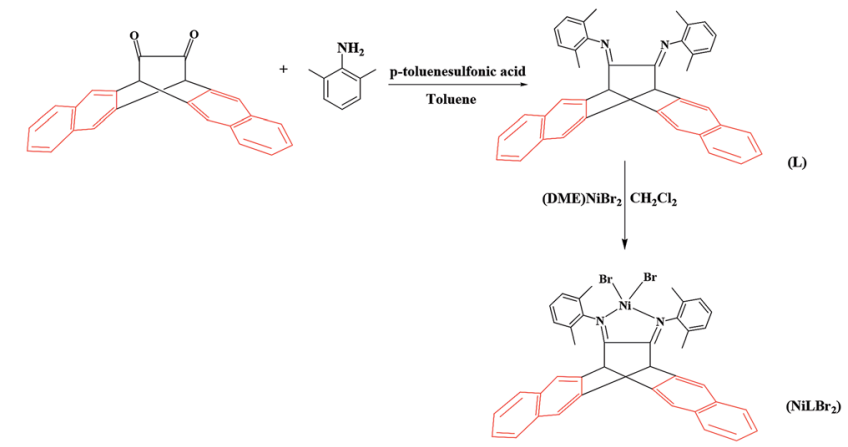

Scheme 1 Synthesis of ( $\alpha$-diimine ligand) nickel dibromide complex.

produced $\alpha$-diimine ligand (Scheme 1). Novel synthesized $\alpha$ diimine ligand formed $\mathrm{NiLBr}_{2}$ complex in good yields (Scheme 1) on reaction with $\mathrm{Ni}(\mathrm{DME}) \mathrm{Br}_{2}$ (DME = dimethoxyethane) in dichloromethane. Due to low solubility in dichloromethane, the crystal structure of $\mathrm{NiLBr}_{2}$ complex could not be obtained and its structure was determined by elemental analysis and NMR spectroscopy.

\section{Homopolymerization of NB}

First of all, NB polymerization activities of the synthesized complex $\mathrm{NiLBr}_{2}$ were investigated with $\mathrm{B}\left(\mathrm{C}_{6} \mathrm{~F}_{5}\right)_{3}$ as cocatalyst and toluene as the reaction solvent. It is well known that catalytic property was depended on the structure of catalyst. To verify that the polycyclic aromatic backbone can improve stability of $\alpha$-diimine nickel complex $\mathrm{NiLBr}_{2}$, a series of norbornene homopolymerization were carried out at different temperature. Table 1 displayed the results of norbornene homopolymerization with $\mathrm{NiLBr}_{2}$ in the temperature range $0-110{ }^{\circ} \mathrm{C}$. The observed basic trend was that the activity of $\mathrm{NiLBr}_{2}$ reached a maximum value at $100{ }^{\circ} \mathrm{C}$ and then decreased with temperature increasing. Even at $110{ }^{\circ} \mathrm{C}$, a high activity $3.75 \times 10^{7} \mathrm{~g}_{\text {polymer }} \mathrm{mol}_{\mathrm{Ni}}{ }^{-1} \mathrm{~h}^{-1}$ can be achieved. $\mathrm{NiLBr}_{2}$ exhibited good thermal stability could be attributed to its rigid and bulky backbone.

\section{Copolymerization of $\mathrm{NB}$ and $\mathrm{NB}-\mathrm{COOCH}_{3}$}

Since $\mathrm{NiLBr}_{2} / \mathrm{B}\left(\mathrm{C}_{6} \mathrm{~F}_{5}\right)_{3}$ system had high activity $\left(4.18 \times 10^{7}\right.$ $\mathrm{g}_{\text {polymer }} \mathrm{mol}_{\mathrm{Ni}}{ }^{-1} \mathrm{~h}^{-1}$ ) toward NB homopolymerization, it was

Table 1 Norbornene polymerization catalyzed by $\mathrm{NiLBr}_{2}$ combined with $\mathrm{B}\left(\mathrm{C}_{6} \mathrm{~F}_{5}\right)_{3}^{a}$

\begin{tabular}{lllll}
\hline No. & $T\left({ }^{\circ} \mathrm{C}\right)$ & $\begin{array}{l}\text { Reaction } \\
\text { time }(\mathrm{min})\end{array}$ & $\begin{array}{l}\text { PNB yield } \\
(\%)\end{array}$ & $\begin{array}{l}\text { Activity }^{b} \\
\left(\mathrm{~g}_{\text {polymer }} \mathrm{mol}_{\mathrm{Ni}}{ }^{-1} \mathrm{~h}^{-1}\right)\end{array}$ \\
\hline 1 & 0 & 30 & 6.38 & 0.18 \\
2 & 30 & 30 & 51.21 & 1.44 \\
3 & 60 & 2 & 80.30 & 33.97 \\
4 & 90 & 2 & 97.93 & 41.43 \\
5 & 100 & 2 & 98.95 & 41.84 \\
6 & 110 & 2 & 88.26 & 37.50
\end{tabular}

${ }^{a}$ Conditions: $n\left[\mathrm{NiLBr}_{2}\right]=5 \times 10^{-6} \mathrm{~mol}$, cocatalyst is $\mathrm{B}\left(\mathrm{C}_{6} \mathrm{~F}_{5}\right)_{3}, \mathrm{~B} /$ complex/monomer $(n / n / n)$ is $5 / 1 / 15000$, the solvent is toluene, the total volume is $22 \mathrm{~mL}$. ${ }^{b}$ In units of $10^{6} \mathrm{~g}_{\text {polymer }} \mathrm{mol}_{\mathrm{Ni}}{ }^{-1} \mathrm{~h}^{-1}$. selected as catalyst to investigate whether it also had high activity toward copolymerization of $\mathrm{NB}$ with $\mathrm{NB}^{-\mathrm{COOCH}_{3}}$. A series of copolymerizations of $\mathrm{NB}$ with $\mathrm{NB}^{-\mathrm{COOCH}_{3}}$ were investigated with the catalyst system of $\mathrm{NiLBr}_{2} / \mathrm{B}\left(\mathrm{C}_{6} \mathrm{~F}_{5}\right)_{3}$ in toluene at $60{ }^{\circ} \mathrm{C}$ for $1 \mathrm{~h}$ under nitrogen atmosphere (Table 2). From the Table 2, we could find that the $\mathrm{NiLBr}_{2} / \mathrm{B}\left(\mathrm{C}_{6} \mathrm{~F}_{5}\right)_{3}$ system exhibited high activity toward copolymerizations of NB with NB$\mathrm{COOCH}_{3}$, which was far higher than the activities of the other $\alpha$ diimine catalysts. ${ }^{34}$ However, $\mathrm{NB}-\mathrm{COOCH}_{3}$ could not be homopolymerized in the same conditions. The reason was that oxygen atom of functionalized NB derivatives competed with the double-bond for the coordination, which led to high concentration of oxygen atom would impede double-bond coordination. ${ }^{35}$

Although the obtained polynorbornene (PNB) were hardly soluble in common organic solvents such as $\mathrm{CHCl}_{3}, \mathrm{CH}_{2} \mathrm{Cl}_{2}$, THF and so on, the copolymers of $\mathrm{NB}$ and $\mathrm{NB}^{-} \mathrm{COOCH}_{3}$ were soluble in these common organic solvents, which exhibited better solubility than PNB. Compared with NB homopolymerization, the yield and activities of copolymerization of NB and $\mathrm{NB}^{-\mathrm{COOCH}_{3}}$ dramatically decreased with the content of NB$\mathrm{COOCH}_{3}$ increasing.

To obtain the reactivity ratios of $\mathrm{NB}$ and $\mathrm{NB}-\mathrm{COOCH}_{3}$ monomers, we changed the polymerization time and the feed content of catalysts to control the conversion rate to be under $10 \%$. The results were shown in Table 3 . The reactivity ratios were determined by the Kelen-TüdÕs method (Fig. 1). ${ }^{36}$ For 6,13-dihydro-6,13-ethanopentacene-15,16-diimine nickel(II) complex $/ \mathrm{B}\left(\mathrm{C}_{6} \mathrm{~F}_{5}\right)_{3}$, the reactivity ratio of $\mathrm{NB}-\mathrm{COOCH}_{3}$ was 0.146 , and the reactivity ratio of $\mathrm{NB}$ was 2.282 .

\section{Characterization of copolymers}

The obtained copolymers were characterized by GPC and the corresponding data were shown in Table 2. The molecular weights of the obtained copolymers were up to $10^{5}$, and the molecular weight distributions MWD of the obtained polymers were all relative narrow $(\mathrm{MWD}<1.5)$.

These obtained copolymers were characterized by spectra (IR, ${ }^{1} \mathrm{H}$ NMR) and thermal analysis (DSC, TGA). In Fig. 2, the signal of double-bond at $1710 \mathrm{~cm}^{-1}$, assigned to the $\mathrm{C}=\mathrm{C}$ bond of the ROMP structure of PNB, was not observed. The signals at about $941 \mathrm{~cm}^{-1}$ could be attributed to the ring of bicyclo[2.2.1] heptanes further illustrating the monomers via vinyl-type addition polymerization. The sharp signals at $1740 \mathrm{~cm}^{-1}$ from the vibration of the carbonyl group were characteristic of ester moieties. This confirmed that the $\mathrm{NB}^{-\mathrm{COOCH}_{3}}$ had been inserted into the chains of the copolymers and to be true vinyltype addition copolymer rather than blend polymer.

Fig. 3 proved that the polymers are vinyl-addition type by the absence of the resonance of the proton hydrogen connected to the double bond at 5.3-5.9 ppm. The peak at 0.7-1.6 ppm could be assigned to methene hydrogen corresponding to $\mathrm{H} 5 / \mathrm{H} 6 / \mathrm{H} 7 /$ $\mathrm{H}^{\prime} / \mathrm{H}^{\prime} / \mathrm{H}^{\prime}$; the peak at 1.6-2.5 ppm could be assigned to the methine hydrogen corresponding to $\mathrm{H} 1 / \mathrm{H} 2 / \mathrm{H} 3 / \mathrm{H} 4 / \mathrm{H}^{\prime} / \mathrm{H}^{\prime}$ / $\mathrm{H}^{\prime} / \mathrm{H}^{\prime}$; the peak at $2.5-2.8 \mathrm{ppm}$ could be attributed to the methine hydrogen corresponding to $\mathrm{H}^{\prime}$; and the characteristic 
Table 2 Copolymerization of NB and NB- $\mathrm{COOCH}_{3}$ catalyzed by $\mathrm{NiLBr}_{2} / \mathrm{B}\left(\mathrm{C}_{6} \mathrm{~F}_{5}\right)_{3}$ system ${ }^{a}$

\begin{tabular}{|c|c|c|c|c|c|c|}
\hline $\mathrm{NB} / \mathrm{NB}-\mathrm{COOCH}_{3}(\mathrm{~mol} / \mathrm{mol})$ & Reaction time (min) & Yield (\%) & Activity $^{b}$ & $M_{\mathrm{w}}^{c}\left(\mathrm{~g} \mathrm{~mol}^{-1}\right)$ & $M_{\mathrm{w}} / M_{\mathrm{n}}{ }^{c}$ & $\mathrm{NB}^{-\mathrm{COOCH}_{3}}{ }^{d}(\mathrm{~mol} \%)$ \\
\hline $100 / 0$ & 2 & 80.30 & $3.40 \times 10^{7}$ & $-^{e}$ & $-^{e}$ & $-^{e}$ \\
\hline $80 / 20$ & 60 & 47.89 & $7.59 \times 10^{5}$ & $3.6 \times 10^{5}$ & 1.1 & 10.2 \\
\hline $50 / 50$ & 60 & 16.87 & $3.11 \times 10^{5}$ & $2.7 \times 10^{4}$ & 1.1 & 28.3 \\
\hline $0 / 100$ & 60 & Trace & $-^{e}$ & $-^{e}$ & $-^{e}$ & $-^{e}$ \\
\hline
\end{tabular}

${ }^{a}$ Conditions: $c[$ Cat. $]=5.0 \times 10^{-6} \mathrm{~mol}$; cocatalyst is $\mathrm{B}\left(\mathrm{C}_{6} \mathrm{~F}_{5}\right)_{3}, \mathrm{~B} /$ complex/monomer $(n / n / n)$ is $10 / 1 / 15000$, polymerization temperature is $60{ }^{\circ} \mathrm{C}$, the solvent is toluene, the total volume is $22 \mathrm{~mL} .{ }^{b}$ In units of $\mathrm{g}_{\text {polymer }} \mathrm{mol}_{\mathrm{Ni}}{ }^{-1} \mathrm{~h}^{-1} \cdot{ }^{c}$ Determined by GPC $v s$. polystyrene standards in THF. ${ }^{d}$ Determined by ${ }^{1} \mathrm{H}$ NMR spectroscopy in $\mathrm{CDCl}_{3} .{ }^{e}$ Not determined.

Table 3 Copolymerization of $\mathrm{NB}$ and $\mathrm{NB}-\mathrm{COOCH}_{3}$ catalyzed by $\mathrm{NiLBr}_{2} / \mathrm{B}\left(\mathrm{C}_{6} \mathrm{~F}_{5}\right)_{3}^{a}$

\begin{tabular}{lllll}
\hline & $\begin{array}{l}\mathrm{NB} / \\
\mathrm{NB}-\mathrm{COOCH}_{3} \\
(\mathrm{~mol} / \mathrm{mol})\end{array}$ & $\begin{array}{l}\text { Time } \\
(\mathrm{h})\end{array}$ & $\begin{array}{l}\text { Yield } \\
(\%)\end{array}$ & $\begin{array}{l}\text { mol\% of } \\
\text { NB-COCH }_{3} \text { in } \text { copolymer }^{b}\end{array}$ \\
\hline 1 & $60 / 40$ & 0.30 & 6.34 & 18.9 \\
2 & $50 / 50$ & 1 & 5.78 & 26.3 \\
3 & $40 / 60$ & 2 & 1.46 & 33.4 \\
4 & $30 / 70$ & 12 & 3.32 & 42.3 \\
5 & $20 / 80$ & 24 & 0.91 & 48.2
\end{tabular}

${ }^{a}$ Conditions: $n\left[\mathrm{NiLBr}_{2}\right]=5 \times 10^{-6} \mathrm{~mol}, \mathrm{~B} /$ complex/monomer $(n / n / n)$ is $5 / 1 / 15000$, the solvent is toluene, the total volume is $22 \mathrm{~mL}$. ${ }^{b}$ Determined by ${ }^{1} \mathrm{H}$ NMR spectroscopy in $\mathrm{CDCl}_{3}$.

peak at 3.4-3.9 ppm was assigned to the methyl hydrogen corresponding to $\mathrm{H}^{\prime}$. The content of $\mathrm{NB}-\mathrm{COOCH}_{3}$ in copolymers was calculated by the following way. ${ }^{37}$

$$
\mathrm{NB}-\mathrm{COOCH}_{3}\left(\mathrm{~mol}^{\%} \%\right)=2 I_{\mathrm{H}^{\prime}} / 3\left(I_{\mathrm{H} 2 / \mathrm{H} 3}+I_{\mathrm{H}^{\prime} / \mathrm{H} 3^{\prime}}\right)
$$

Where $I_{\mathrm{H}^{\prime}}$ represented the area of the methyl in the NB$\mathrm{COOCH}_{3}, I_{\mathrm{H} 2 / \mathrm{H} 3}$ represented the area of the position $\mathrm{H} 2$ and $\mathrm{H} 3$ methine in the $\mathrm{NB}$, and $I_{\mathrm{H}^{\prime} / \mathrm{H}^{\prime}}$ represented the area of the position $\mathrm{H}_{2}^{\prime}$ and $\mathrm{H}^{\prime}$ methine in the $\mathrm{NB}^{\prime} \mathrm{COOCH}_{3}$.

The results of calculated $\mathrm{NB}-\mathrm{COOCH}_{3}$ content were presented in Table 2 . It could be observed that the content of NB-

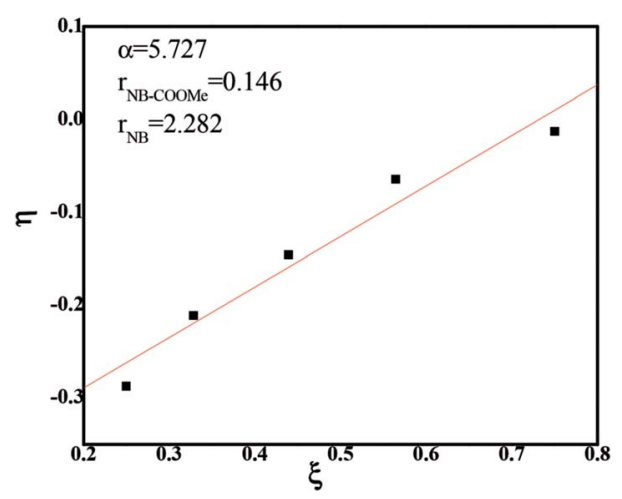

Fig. 1 Linear fitting of the NB/NB-COOCH${ }_{3}$ copolymers catalyzed by $\mathrm{NiLBr}_{2} / \mathrm{B}\left(\mathrm{C}_{6} \mathrm{~F}_{5}\right)_{3}$ systems according to Kelen-TÜdÕs method.

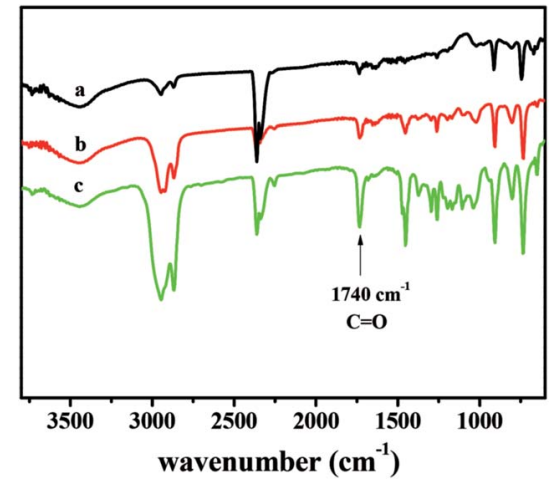

Fig. 2 FTIR spectra of poly(NB-CO-NB-COOCH ) with (a) $10.2 \%$, (b) $19.4 \%$, and (c) $28.3 \%$ of $\mathrm{NB}-\mathrm{COOCH}_{3}$ molar ratios separate obtained by $\mathrm{NiLBr}_{2} / \mathrm{B}\left(\mathrm{C}_{6} \mathrm{~F}_{5}\right)_{3}$ systems

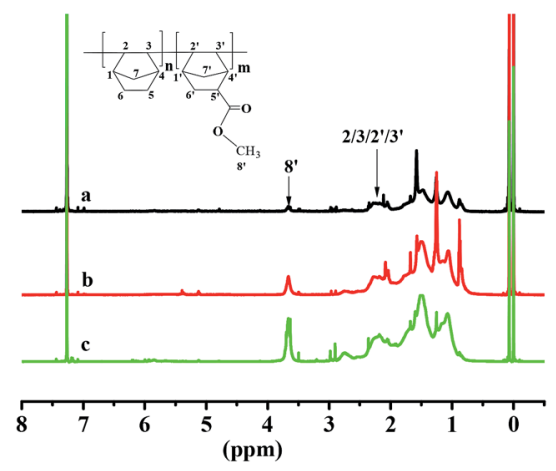

Fig. $3{ }^{1} \mathrm{H}$ NMR spectra of poly(NB-CO-NB-COOCH${ }_{3}$ ) with (a) $10.2 \%$, (b) $19.4 \%$, and (c) $28.3 \%$ of $\mathrm{NB}-\mathrm{COOCH}_{3}$ molar ratios separate obtained by $\mathrm{NiLBr}_{2} / \mathrm{B}\left(\mathrm{C}_{6} \mathrm{~F}_{5}\right)_{3}$ system.

$\mathrm{COOCH}_{3}$ in copolymers was calculated from 10.2 to $28.3 \%$ by varying the comonomer feed ratios $\left(\mathrm{NB}-\mathrm{COOCH}_{3} / \mathrm{NB}\right)$ from 10 to $50 \%$.

The TGA curves of the copolymers with different NB$\mathrm{COOCH}_{3}$ content prepared by $\mathrm{NiLBr}_{2} / \mathrm{B}\left(\mathrm{C}_{6} \mathrm{~F}_{5}\right)_{3}$ were shown in Fig. 4. The decomposition temperatures $\left(T_{\mathrm{d}}\right) \mathrm{s}$ of the polymers were as high as $339.6-377.7{ }^{\circ} \mathrm{C}$ and decreased with the increasing of $\mathrm{NB}-\mathrm{COOCH}_{3}$ content in copolymers, which was similar to the transition temperatures. 


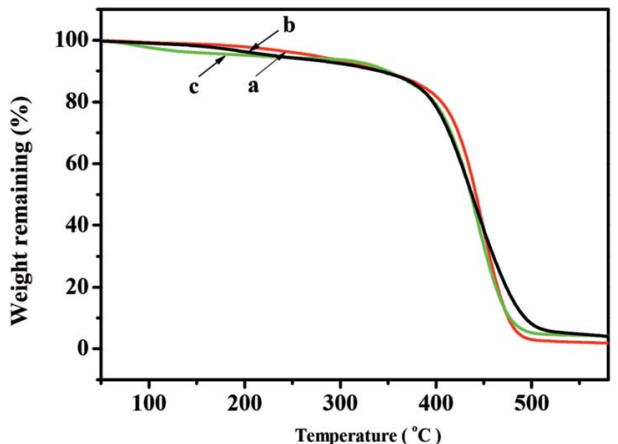

Fig. 4 TGA curves of poly(NB-CO-NB-COOCH$\left.{ }_{3}\right)$ with(a) $10.2 \%$, (b) $19.4 \%$, and (c) $28.3 \%$ of $\mathrm{NB}-\mathrm{COOCH}_{3}$ molar ratios separate obtained by $\mathrm{NiLBr}_{2} / \mathrm{B}\left(\mathrm{C}_{6} \mathrm{~F}_{5}\right)_{3}$ systems. The $\left(T_{\mathrm{d}}\right) \mathrm{s}$ of the polymers are: (a) $377.7^{\circ} \mathrm{C}$, (b) $364.5^{\circ} \mathrm{C}$, (c) $339.6^{\circ} \mathrm{C}$.

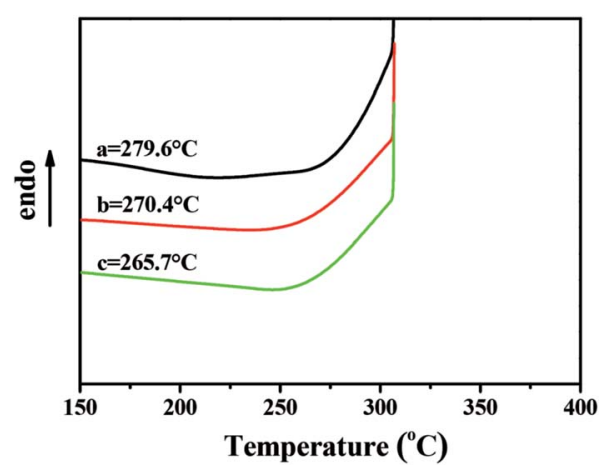

Fig. 5 DSC curves of poly(NB-CO-NB-COOCH$)_{3}$ with (a) $10.2 \%$, (b) $19.4 \%$, and (c) $28.3 \%$ of $\mathrm{NB}-\mathrm{COOCH}_{3}$ molar ratios separate obtained by $\mathrm{NiLBr}_{2} / \mathrm{B}\left(\mathrm{C}_{6} \mathrm{~F}_{5}\right)_{3}$ systems.

The DSC curves and glass transition temperatures $\left(T_{\mathrm{g}}\right) \mathrm{s}$ of the copolymers with different $\mathrm{NB}-\mathrm{COOCH}_{3}$ ratio prepared by $\mathrm{NiLBr}_{2} / \mathrm{B}\left(\mathrm{C}_{6} \mathrm{~F}_{5}\right)_{3}$ were shown in Fig. 5 . The $\left(T_{\mathrm{g}}\right) \mathrm{s}$ of the polymers were reduced to $265.7-279.6{ }^{\circ} \mathrm{C}$ when the content of NB$\mathrm{COOCH}_{3}$ increased in the copolymers.

All the copolymers, irrespective of the polymerization conditions employed showed identical powder WXRD pattern. Fig. 6 showed the WXRD curves of the copolymers with different

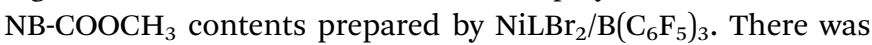
no trace of Bragg reflection in the characteristic of crystalline regions, so the polymers were noncrystalline. The occurrence of two halos at $2 \theta$ values of $9.72-10.95^{\circ}$ (peak 1 ) and $18.07-19.80^{\circ}$ (peak 2) were characteristic for PNB. ${ }^{38}$

\section{Experimental}

\section{Materials}

All the reactions were performed under an atmosphere of dry and oxygen-free argon using standard vacuum, Schlenk, or under nitrogen atmosphere in glove box (M Braun). Toluene and hexane were refluxed over metallic sodium for 24 hours before being used. Dichloromethane was dried over $\mathrm{CaH}_{2}$ for 8 hours and distilled under a nitrogen atmosphere. NB was purchased from Alfa Aesar and purified through drying by

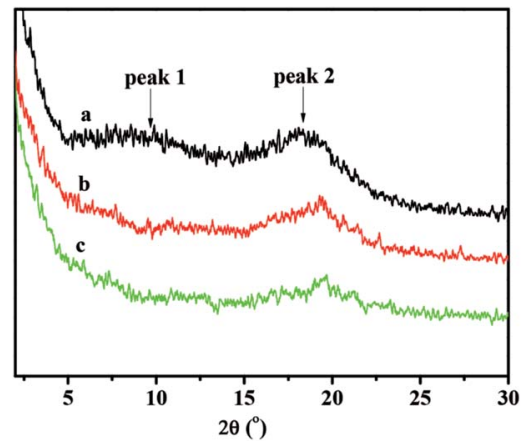

Fig. 6 WXRD curves of poly(NB-CO-NB-COOCH${ }_{3}$ ) with(a) $10.2 \%$, (b) $19.4 \%$, and (c) $28.3 \%$ of NB- $\mathrm{COOCH}_{3}$ molar ratios separate obtained by $\mathrm{NiLBr}_{2} / \mathrm{B}\left(\mathrm{C}_{6} \mathrm{~F}_{5}\right)_{3}$ systems.

sodium and distilled under dry nitrogen, then made a solution in toluene. $\mathrm{NB}^{-\mathrm{COOCH}_{3}}$ was purchased from Aldrich and purified by $\mathrm{CaH}_{2}$. Other commercially available reagents were purchased and used without purification.

\section{General}

The element analysis was performed on elementar-vario EL cube elemental analyzer. The nuclear magnetic resonance (NMR) was recorded on a Bruker ARX 400 NMR spectrometer at ambient temperature, with $\mathrm{CDCl}_{3}$ as the solvent. Chemical shifts for the ${ }^{1} \mathrm{H}$ NMR and ${ }^{13} \mathrm{C}$ NMR spectrum were given in parts per million from the peak for internal tetramethylsilane. The gel permeation chromatography (GPC) was conducted with a Breeze Waters system using polystyrenes as the standard and tetrahydrofuran as the eluent at a flow rate of $1.0 \mathrm{~mL} \mathrm{~min}^{-1}$. The IR spectra were recorded by a Shimadzu IR Prestige-21 FTIR spectrophotometer. The wide-angle X-ray diffraction (WXRD) curves were recorded on a Bruker D8 Focus X-ray diffractometer, operating at $40 \mathrm{kV}$ and $40 \mathrm{~mA}$ with a copper target $(\lambda=1.54 \AA)$ and at a scanning rate of $2^{\circ} \mathrm{min}^{-1}$. The thermal gravimetric analysis (TGA) measurements were performed on a PerkinElmer instrument TGA 7 from room temperature to $700{ }^{\circ} \mathrm{C}$ at a rate of $10{ }^{\circ} \mathrm{C} \min ^{-1}$ under nitrogen atmosphere. The differential scanning calorimetry (DSC) measurements were obtained on a Shimadzu DSC-60 with a heating/cooling rate of $10{ }^{\circ} \mathrm{C} \min ^{-1}$ under nitrogen atmosphere.

\section{Synthesis of $\alpha$-diimine ligand (L)}

Under a nitrogen atmosphere, to a solution of $3.0 \mathrm{mmol}$ of the 2,6-dimethyl aniline in $150 \mathrm{~mL}$ toluene, $1.0 \mathrm{mmol}$ of 6,13dihydro-6,13-ethanopentacene-15,16-dione and a catalytic amount of $p$-toluenesulfonic acid were added. The mixture was heated under reflux in the dark. The resulting water was removed as azeotropic mixture using a Dean-Stark apparatus. After 24 hours, the reaction mixture was cooled to room temperature and evaporated at reduced pressure. The residual solids were further purified by silica column chromatography (v/v, 10/1, petroleum ether/ethyl acetate) and were crystallized from the mixture of petroleum ether and ethyl acetate to get the product as yellow crystals in $42.5 \%$ yield. The $\alpha$-diimine ligand 
was characterized by elemental analysis and ${ }^{1} \mathrm{H}$ and ${ }^{13} \mathrm{C}$ NMR spectroscopy. Mp: 228-229 ${ }^{\circ} \mathrm{C}$. Elemental analysis (\%), found: C, 88.61; H, 6.10; N, 5.29; calcd: C, 88.85; H, 5.97; N, 5.18. ${ }^{1} \mathrm{H}$ $\mathrm{NMR}\left(\mathrm{CDCl}_{3}, \delta, \mathrm{ppm}\right): 1.90(\mathrm{~s}, 12 \mathrm{H}), 4.88(\mathrm{~s}, 2 \mathrm{H}), 7.05-7.28(\mathrm{~m}$, $6 \mathrm{H}), 7.54(\mathrm{~m}, 4 \mathrm{H}), 7.88(\mathrm{~m}, 4 \mathrm{H}), 7.96(\mathrm{~s}, 4 \mathrm{H}) .{ }^{13} \mathrm{C} \mathrm{NMR}\left(\mathrm{CDCl}_{3}, \delta\right.$, ppm): 17.82, 51.43, 124.51, 125.61, 126.08, 127.71, 128.39, 131.52, 133.74, 136.05, 148.10, 160.24 .

\section{Synthesis of ( $\alpha$-diimine ligand) nickel dibromide complex $\left(\mathrm{NiLBr}_{2}\right)$}

$0.2 \mathrm{mmol} \alpha$-diimine ligand (L) and $0.2 \mathrm{mmol}$ dimethoxymethane nickel dibromide were added to a Schlenk tube together with $10 \mathrm{~mL}$ dried dichloromethane, the reaction mixture was then stirred for $8 \mathrm{~h}$ at room temperature and $10 \mathrm{~mL}$ absolute hexane was added. The dark red crystal ( $\alpha$-diimine ligand) nickel dibromide complex $\left(\mathrm{NiLBr}_{2}\right)$ was crystallized from the mixture of dichloromethane and hexane in $82 \%$ yield. Complex $\mathrm{NiLBr}_{2}$ was characterized by elemental analysis and ${ }^{1} \mathrm{H}$ NMR spectroscopy. Mp: 342-344 ${ }^{\circ} \mathrm{C}$. Elemental analysis (\%), found: C, 62.96; H, 4.36; N, 3.84; calcd: C, 63.28; H, 4.25; N, 3.69. ${ }^{1} \mathrm{H}$ NMR $\left(\mathrm{CDCl}_{3}, \delta, \mathrm{ppm}\right): 1.92(\mathrm{~s}, 12 \mathrm{H}), 4.95$ (s, 2H), 7.04-7.30 (m, 6H), $7.56(\mathrm{~m}, 4 \mathrm{H}), 7.91(\mathrm{~m}, 4 \mathrm{H}), 7.97$ (s, 4H).

\section{Homopolymerization of NB}

In a typical procedure, the appropriate $\mathrm{B}\left(\mathrm{C}_{6} \mathrm{~F}_{5}\right)_{3}$ solid was introduced into the round-bottom glass flask, and then a certain amount of a toluene solution of NB and quantitative nickel complex $\mathrm{NiLBr}_{2}$ solution were syringed into the wellstirred solution in order, and the reaction mixture was continuously stirred for an designed period at the polymerization temperature. Polymerizations were terminated by addition of the acidified ethanol $(\mathrm{v} / \mathrm{v}, 10 / 1$, ethanol/HCl) and stayed overnight. The polymers were then obtained through filtration or centrifugation and washed by ethanol several times and were dried at $40{ }^{\circ} \mathrm{C}$ to a constant weight.

\section{Polymerization of norbornene (NB) and 5-norbornene-2- carboxylic acid methyl ester $\left(\mathrm{NB}-\mathrm{COOCH}_{3}\right)$}

A typical procedure was as follows: the appropriate $\mathrm{B}\left(\mathrm{C}_{6} \mathrm{~F}_{5}\right)_{3}$ solid was introduced into the $100 \mathrm{~mL}$ round-bottom glass flask, then a certain amount of toluene solution of $\mathrm{NB}, \mathrm{NB}-\mathrm{COOCH}_{3}$, and appropriate amount of catalyst were syringed into the well stirred solution in order, and the reaction was continuously stirred for an appropriate period at the polymerization temperature. The polymerization was stopped by addition of acidic ethanol (v/v, 10/1, ethanol/HCl) and stayed overnight. The polymers were then obtained through filtration or centrifugation and washed by ethanol several times and were dried at $40{ }^{\circ} \mathrm{C}$ to a constant weight.

\section{Conclusions}

The 6,13-dihydro-6,13-ethanopentacene-15,16-diimine nickel(II) complex with large steric hindrance of polycyclic aromatic systems on the backbone was synthesized and characterized. The new 6,13-dihydro-6,13-ethanopentacene-15,16-diimine
nickel(II) complex on NB polymerization showed high activities even up to $4.18 \times 10^{7} \mathrm{~g}_{\text {polymer }} \mathrm{mol}_{\mathrm{Ni}}{ }^{-1} \mathrm{~h}^{-1}$. Meanwhile, the complex also displayed high activity toward the copolymerization of $\mathrm{NB}$ and $\mathrm{NB}-\mathrm{COOCH}_{3}$. The complex with big hindrance on backbone was found to show good thermal stability for NB polymerization and afford high-molecular-weight copolymers with high incorporation of polar monomer. These findings identify a promising strategy to explore new catalysts with stability and good tolerance to polar comonomer by designing bulkier backbone $\alpha$-diimine catalytic systems.

\section{Conflicts of interest}

There are no conflicts to declare.

\section{Acknowledgements}

This work was supported by the National Natural Science Foundation of China (21664014), the Natural Science Foundation of Jiangxi Province (20151BAB206021 and 20161BAB215197).

\section{Notes and references}

1 C. Janiak and P. G. Lassahn, J. Mol. Catal. A: Chem., 2001, 166, 193.

2 N. R. Grove, P. A. Kohl, S. A. B. Allen, S. Jayaraman and R. Shick, J. Polym. Sci., Part B: Polym. Phys., 1999, 37, 3003.

3 S. Ahmed, S. A. Bidstrup, P. A. Kohl and P. J. Ludovice, J. Phys. Chem. B, 1998, 102, 9783.

4 K. Ziegler, E. Holzkamp, H. Breil and H. Martin, Angew. Chem., 1955, 67, 541.

5 G. Natta, P. Pino, P. Corradini, F. Dannusso, E. Mantica, G. Mazzanti and G. Moraglio, J. Am. Chem. Soc., 1955, 77, 1708.

6 A. El-Batta, A. W. Waltman and R. H. Grubbs, J. Organomet. Chem., 2011, 696, 2477.

7 N. Diteepeng, X. Y. Tang, X. H. Hou, Y. S. Li, K. Phomphrai and K. Nomuraa, Dalton Trans., 2015, 44, 12273.

8 L. Piche, J. C. Daigle, G. Rehse and J. P. Claverie, Chem.-Eur. J., 2012, 18, 3277.

9 Q. Xing, T. Zhao, Y. Qiao, L. Wang, C. Redshaw and W. H. Sun, RSC Adv., 2013, 3, 26184.

10 M. P. Weberski Jr, L. Chen, M. Delferro and T. J. Marks, Chem.-Eur. J., 2012, 18, 10715.

11 A. Sachse, S. Demeshko, S. Dechert, V. Daebel, A. Lange and F. Meyer, Dalton Trans., 2010, 39, 3903.

12 M. P. Weberski, C. Chen, M. Delferro, C. Zuccaccia, A. Macchioni and T. J. Marks, Organometallics, 2012, 31, 3773.

13 L. H. Guo, H. Y. Gao, Q. R. Guan, H. B. Hu, F. S. Liu and Q. Wu, Organometallics, 2012, 31, 6054.

14 H. B. Hu, H. Y. Gao, D. R. Chen, G. L. Li, Y. X. Tan, G. D. Liang, F. M. Zhu and Q. Wu, ACS Catal., 2015, 5, 122. 15 L. K. Johnson, C. M. Killian and M. Brookhart, J. Am. Chem. Soc., 1995, 117, 6414. 
16 C. M. Killian, D. J. Tempel, L. K. Johnson and M. Brookhart, J. Am. Chem. Soc., 1996, 118, 11664.

17 B. L. Small, M. Brookhart and A. M. A. Bennett, J. Am. Chem. Soc., 1998, 120, 4049.

18 H. D. Mkoyi, S. O. Ojwach, I. A. Guzei and J. Darkwa, J. Organomet. Chem., 2013, 724, 95.

19 L. H. Guo and C. L. Chen, Sci. China: Chem., 2015, 58, 1663.

20 H. Liu, W. Z. Zhao, X. Hao, C. Redshaw, W. Huang and W. H. Sun, Organometallics, 2011, 30, 2418.

21 F. Zhai and R. F. Jordan, Organometallics, 2017, 36, 2784.

22 B. Liu, M. Z. Fang, S. Y. Jie, Z. Y. Bu and B. G. Li, Chin. J. Polym. Sci., 2016, 34, 221.

23 A. Meduri, T. Montini, F. Ragaini, P. Fornasiero, E. Zangrando and B. Milani, ChemCatChem, 2013, 5, 1170.

24 J. L. Rhinehart, L. A. Broen and B. K. Long, J. Am. Chem. Soc., 2013, 135, 16316.

25 S. Y. Dai, X. L. Sui and C. L. Chen, Angew. Chem., Int. Ed., 2015, 54, 9948.

26 C. S. Popeney, C. M. Levins and Z. B. Guan, Organometallics, 2011, 30, 2432.

27 F. S. Liu, H. Y. Gao, Z. L. Hu, H. B. Hu, F. M. Zhu and Q. Wu, J. Polym. Sci., Part A: Polym. Chem., 2012, 50, 3859.
28 D. H. Leung, J. W. Ziller and Z. B. Guan, J. Am. Chem. Soc., 2008, 130, 7538.

29 D. H. Camacho, E. V. Salo, J. W. Ziller and Z. B. Guan, Angew. Chem., Int. Ed., 2004, 43, 1821.

30 L. H. Guo, H. Y. Gao, Q. R. Guan, H. B. Hu, J. A. Deng, J. Liu, F. S. Liu and Q. Wu, Organometallics, 2012, 31, 6054.

31 J. Liu, D. R. Chen, H. Wu, Z. F. Xiao, H. Y. Gao, F. M. Zhu and Q. Wu, Macromolecules, 2014, 47, 3325.

32 S. Z. Du, S. L. Kong, Q. S. Shi, J. Mao, C. Y. Guo, J. J. Yi, T. L. Liang and W. H. Sun, Organometallics, 2015, 34, 582.

33 D. D. Jia, W. J. Zhang, W. L. Liu, L. Wang, C. Redshaw and W. H. Sun, Catal. Sci. Technol., 2013, 3, 2737.

34 P. Huo, W. Y. Liu, X. H. He, Z. H. Wei and Y. W. Chen, Polym. Chem., 2014, 5, 1210.

35 P. Huo, W. Y. Liu, X. H. He, H. M. Wang and Y. W. Chen, Organometallics, 2013, 32, 2291.

36 T. Kelen and F. J. TüdÕs, J. Macromol. Sci., Part A, 1975, 9, 1. 37 Y. P. Xing, Y. W. Chen and X. H. He, J. Polym. Sci., Part A: Polym. Chem., 2011, 49, 4425.

38 X. Mi, L. Wang, Y. C. Ke and Y. L. Hu, Macromol. Chem. Phys., 2003, 204, 868. 